\title{
Transcriptomic response of Enterococcus faecalis V583 to low hydrogen peroxide levels
}

Yan Xue 1, Budin-Verneuil Aurelie 1, Verneuil Nicolas ${ }^{1}$, Gilmore Michael S. ${ }^{2}$, Artigaud Sebastien ${ }^{3}$, Auffray Yannick ${ }^{1}$, Pichereau Vianney ${ }^{1,3,}{ }^{*}$

1 Univ Caen Basse Normandie, Unite Rech Risques Microbiens U2RM, Equipe Stress Virulence, F14032 Caen, France.

${ }^{2}$ Harvard Univ, Sch Med, Dept Ophthalmol, Boston, MA USA.

3 Univ Bretagne Occidentale UEB, Lab Sci Environm Marin LEMAR, Inst Univ Europeen Mer, IFREMER,IRD,UBO,CNRS,UMR 6539, F-29280 Plouzane, France.

* Corresponding author : Vianney Pichereau, email address : vianney.pichereau@univ-brest.fr

\begin{abstract}
:
Enterococcus faecalis is a Gram-positive commensal bacterium inhabiting the gastrointestinal tracts of human and other mammals, but is also increasingly recognized as an opportunistic human pathogen. Oxidative stress is one of the major challenges encountered by enterococci, both in their natural environment and during infection. In this paper, we evaluated the transcriptomic response of $\mathrm{E}$. faecalis to oxidative stress, and showed that transcript abundance was reduced for 93 genes and increased for 39 genes during growth in medium containing $1.75 \mathrm{mM} \mathrm{H} 2 \mathrm{O} 2$. The presence of hydrogen peroxide affected several metabolic pathways, including a large decrease in ethanolamine utilization and methylglyoxal metabolism, and an increase in transcript abundance for several transport systems. In particular, four operons encoding iron transporters appeared highly induced. By contrast, in our experimental conditions, the expression of most of the genes known to be involved in the enterococcal response to oxidative stress, did not appear significantly altered.
\end{abstract}




\section{Introduction}

Enterococcus faecalis is a Lactic Acid Bacterium naturally inhabiting the gastrointestinal tracts of humans and other mammals, and used as a constituent of some probiotic food supplements $[17,18,30]$. However, E. faecalis also can cause life-threatening infections in humans, especially in the hospital environment $[35,46]$. Oxidative stress is one of the major challenges encountered by E. faecalis during its life cycle [23,34,50]. Nearly two decades of research have revealed that this bacterium possesses genes encoding antioxidant enzymes such as sodA (Superoxide dismutase, [41]), katA (Catalase, [14]), gor (Glutathione reductase), nox (NADH oxidase), trx (Thioredoxine reductase), dps (DNA-binding protein), msrA (Peptide methionine-S-sulfoxide reductase) [39], $n p r$ (NADH peroxidase, [44]), ohr (Organic hydroperoxide resistance protein, [43]), ahpC (Alkyl hydroperoxide reductase, [57]), ahpF (Peroxiredoxine reductase), and several transcriptional regulators involved in the oxidative stress response, as hypR [55], perR, fur, zur [56], soxS [54].

Global experimental approaches that allow monitoring of gene and protein expression (i.e., transcriptomics and proteomics, respectively) in response to a particular environmental condition, constitute powerful tools to understand the metabolic and regulatory networks involved in stress adaptation on a genome-wide scale. To date, only one proteomic study examined changes in expression of 23 proteins in E. faecalis cells exposed to hydrogen peroxide $\left(\mathrm{H}_{2} \mathrm{O}_{2}\right)$ [12]. In this paper, we report global changes in transcript abundance in $E$. faecalis V583 during growth in the presence of $\mathrm{H}_{2} \mathrm{O}_{2}$. 


\section{Materials and methods}

\subsection{Bacterial strains and growth conditions}

In this work, we used E. faecalis V583 ery ${ }^{\mathrm{S}}$, an erythromycin sensitive derivative of the clinical isolate E. faecalis V583 [45]. Cells were cultivated with shaking in M17 medium supplemented with $0.5 \%$ (w/vol) glucose (GM17), supplemented with $\pm 1.75 \mathrm{mM} \mathrm{H}_{2} \mathrm{O}_{2} 2.2$.

\section{Microarray experiments}

V583 ery ${ }^{\mathrm{S}}$ growth was monitored spectrophotometrically at $600 \mathrm{~nm}$. When the culture reached mid-exponential phase (Fig. 1), cells were harvested and total RNA was extracted, purified, and residual DNA enzymatically removed as described previously [59]. Two independent experiments were performed for each condition. cDNA preparation, fragmentation, labeling and hybridization were performed as described in the Affymetrix manual ("GeneChip Expression Analysis Technical Manual: Procaryotic Target preparation" P/N 702232 Rev 2). Washing and scanning were performed using a GeneChip ${ }^{\circledR}$ Fluidics Station 450. The arrays were read at $570 \mathrm{~nm}$ with a resolution of $1.56 \mu \mathrm{m}$ using an Affymetrix GeneChip Scanner 3000 7G (Affymetrix). Results were analyzed and compared using the GeneChip Operating Software (GCOS) version 1.4. Data were also analysed using R (version 3.0.0; $\mathrm{R}$ core team, 2013) and the Bioconductor software (version 2.12; [15]), to perform a t-test with a Benjamini and Hochberg multiple testing correction cut-off of $\mathrm{P}<0.05$ (data not shown). In all, we considered differences in transcript abundance significant if by GCOS they exhibited both a p-value below 0.05 , and an absolute expression ratio significantly greater than 2 fold.

\subsection{Real-Time quantitative PCR}

Real-Time qPCR was performed exactly as described by Giard et al. [16]. Specific primers were designed using the Primer3 software available at the web site http://frodo.wi.mit.edu/cgibin/primer3/primer3_www.cgi (Table 1) with the following 
parameters: amplicon length (99 to $101 \mathrm{bp}$ ), primer length (19 to 21 nucleotides), and primer melting temperature (Tm from 59 to $61{ }^{\circ} \mathrm{C}$ ). Total RNAs, treated with DNase I (GE Healthcare) and purified using the DNA-free kit (Ambion), were reverse transcribed using the Omniscript enzyme (Qiagen) and random hexamer primers according to the manufacturer's recommendations. RT qPCR was performed using the QuantiTect SYBR Green RT PCR kit (Qiagen). Quantification of 23S rRNA transcript levels was used as an internal control. All experiments were performed twice, and in duplicate with two different RNA samples, using the BioRad iCycler iQ detection system (Bio-Rad Laboratories, Richmond, CA). The value used for the comparison of genes expressions in stressed and unstressed cells was the number of PCR cycles required to reach the threshold cycle $\left(C_{T}\right)$. To relate the $C_{T}$ value to the abundance of an mRNA species, $C_{T}$ was converted to " $n$-fold difference" by comparing mRNA abundance in the control cells to that obtained with the $\mathrm{H}_{2} \mathrm{O}_{2}$ stressed cells. The $n$-fold difference was calculated by the formula $\left(\mathrm{n}=2^{-x}\right)$ when the $C_{T \text { mutant }}<C_{T}$ v583 and $\left(\mathrm{n}=-2^{x}\right)$ when $C_{T \text { mutant }}>C_{T \text { v583}}$, with x $=\left(C_{T \text { mutant }}-C_{T \text { v583 }}\right)$.

\section{Results and discussion}

\subsection{Growth of E. faecalis V583 ery $\mathrm{S}$ under oxidative stress.}

E. faecalis cells were cultured in the presence of increasing concentrations of $\mathrm{H}_{2} \mathrm{O}_{2}$, from 1.5 $\mathrm{mM}$ to $2 \mathrm{mM}$ to identify a condition where $\mathrm{H}_{2} \mathrm{O}_{2}$ had a detectable effect on growth, but where cells were also able to successfully respond to the challenge. Results presented in the Fig. 1 showed that the inhibitory effect of $\mathrm{H}_{2} \mathrm{O}_{2}$ was mainly observable on the duration of the Lag phase, which increased from approx. $30 \mathrm{~min}$ to $3 \mathrm{~h}$ in the presence of $1.5 \mathrm{mM}$ to $2 \mathrm{mM} \mathrm{H}_{2} \mathrm{O}_{2}$. We aimed at determining the effects of low doses of $\mathrm{H}_{2} \mathrm{O}_{2}$ on the global genes expression profiles of exponentially growing E. faecalis cells, which were previously shown to display differences in stress tolerance [12]. Therefore, total RNAs were extracted from 
116 mid-exponential growth phase cells (Fig. 1), and then processed for transcriptome analyses.

3.2. Transcriptome changes in response to $\mathrm{H}_{2} \mathrm{O}_{2}$ exposure.

118 Whole genome expression profiling of E. faecalis V583 was performed using affymetrix

119 chips, using total RNAs extracted from both unstressed- and stressed- $\left(1.75 \mathrm{mM} \mathrm{H} \mathrm{H}_{2} \mathrm{O}_{2}\right)$

120 cultures at an $\mathrm{OD}_{600 \mathrm{~nm}}$ of 0.6 (reached two and four hours after inoculation, respectively, Fig.

121 1). Comparative analysis showed that 132 genes were significantly differentially expressed in

122 response to $1.75 \mathrm{mM} \mathrm{H}_{2} \mathrm{O}_{2}$, considering a ratio threshold of two fold (Tables 2 and 3). We

123 selected 25 of the mostly deregulated genes, and subjected them to RT-qPCR (Table 4). It is

124 noteworthy that we showed a very strong correlation $\left(r^{2}=0.86\right)$ between the changes in genes

125 expression observed with the whole genome transcriptomic- and the qPCR- experimental

126 approaches.

127 Among the 132 genes for which transcript abundance changes significantly, 93 showed 128 reduction and 39 were found to be increased. We classified these 132 genes into 9 groups

129 according to the categories described in the comprehensive microbial resource of The Institute 130 of Genome Research (http://www.tigr.org/tigr-scripts/CMR2/CMRHomePage.spl/). Figure 2 131 shows the number of differentially regulated genes in each functional class. The main 132 observation is the large dominance of genes encoding proteins for which the function is 133 annotated as unknown (60), and the abundance of genes encoding (i) transport and binding 134 proteins (22 genes increased and 3 reduced), (ii) proteins involved in biosynthesis and 135 metabolism (4 increased and 24 reduced), and (iii) proteins involved in regulation and cell 136 signaling (8). Transcripts for only two genes annotated as involved in stress adaptation and 137 virulence were found to be changed.

138 3.3. Classification of genes by their regulation patterns.

139 Table 2 and Table 3 identify genes associated with increased and decreased levels of mRNA, 140 respectively, as a result of exposure to $1.75 \mathrm{mM} \mathrm{H}_{2} \mathrm{O}_{2}$. The most highly affected transcripts 
141 are changed by about 10 fold. For example, the ef3082-ef3085 operon encoding the 4

142 components of an iron compound $\mathrm{ABC}$ transport system, displayed increased transcript

143 abundance from 9 to 11 fold, while the greatest decreases all related to ethanolamine

144 metabolism, and displayed a reduction in transcript abundance reaching almost 12 fold.

145 To understand these changes in the global context of cellular metabolism, we searched for

146 functional association networks using the STRING program ([13], available at

147 http://string-db.org/). Results presented in Fig. 3 show that of the 132 genes for which

148 significant transcript changes were observed, only 14 were disconnected from any node, and

149 only 22 belonged to networks that included less than 4 partners (thus showing that $73 \%$ of the

150 genes affected by $\mathrm{H}_{2} \mathrm{O}_{2}$ stress belonged to larger networks).

151 Gene ontology enrichment analyses showed that the main biological processes and molecular

152 functions associated with global transcriptional change, again were those related to metal ion 153 transport and ethanolamine metabolism P-values $<10^{-5}$ for each).

$154 \quad$ 3.3.1. Metabolism

\section{Ethanolamine metabolism}

156 Both microarray and real time q-PCR (Table 3 and Table 4) showed that $\mathrm{H}_{2} \mathrm{O}_{2}$ decreased the

157 the abundance of transcripts for 18 genes belonging to the eut operon involved in 158 ethanolamine metabolism. Ethanolamine (EA) is an abundant compound in the human 159 intestinal tract [24,26] and in processed food [7], and can be used as a source of carbon, 160 nitrogen, and energy. However, growth of the V583 strain, and of RR17 (ef1633) a null 161 mutant of ef1633, showed that EA provided with CoB12 allowed E. faecalis to grow, albeit 162 poorly, only under anaerobic conditions, and the RR17 response regulator was required for 163 this effect. A promoter upstream of RR17 is induced by EA-CoB12 in anaerobiosis [38]. The 164 observation that most of the genes from EF1617 (eutQ) to EF1638 (eutP) were highly 165 repressed by $\mathrm{H}_{2} \mathrm{O}_{2}$ in this study, could stem from a negative impact of $\mathrm{H}_{2} \mathrm{O}_{2}$ on either EA 
and/or CoB12 in the medium, and reflects an important modulation of metabolism in

167 enterococcal cells in response to oxidative stress. It is noteworthy that the Eut system was also shown to be negatively deregulated in (i) a microarray study of the Fsr system [5], and (ii) in relA mutants unable to produce (p)ppGpp $[59,60]$ and unpublished data), showing that the regulation of the Eut operon is governed by many inputs. This new data adds to the

171 understanding of the role of this system in the physiology of bacteria subjected to changing

172 environments.

173 Methylglyoxal metabolism

174 The production of MG (methylglyoxal) in bacterial cells is maintained in balance with the 175 capacity for detoxification and protection against this toxic electrophile, which can react with 176 the nucleophilic centres of macromolecules such as DNA, RNA and proteins [4,11]. Table 3 177 and Table 4 show that the abundance of transcripts for 3 genes encoding glyoxalase family 178 proteins (among the 9 genes identified in the genome with related function) is significantly 179 reduced during the growth in the presence of $\mathrm{H}_{2} \mathrm{O}_{2}$. It should be noted that all other 180 glyoxalase genes, and the ef0939 gene encoding the methyl glyoxal synthase, were also 181 negatively impacted, but by differences $<2$ fold (Table 5). This indicates an important role 182 for methylglyoxal metabolism under this stress. In enteric bacteria, three methylglyoxal 183 detoxification routes have been identified, i.e. the glutathione-dependent glyoxalase I-II system [19], (ii) glutathione-independent glyoxalase III [31], and (iii) methylglyoxal 185 reductases and dehydrogenases [19,32]. The 5 glyoxalase genes for which mRNA abundance 186 decreased in the presence of $\mathrm{H}_{2} \mathrm{O}_{2}$ share sequence identity with genes of the glyoxalase I-II 187 system. Although methylglyoxal is considered as an extremely toxic electrophile, potentially 188 leading to the death of bacterial cell, several studies suggest that this compound is important 189 for bacterial homeostasis. Indeed, methylglyoxal is thought to be important in bacteria for 190 growth regulation, D-lactate production [8], the uncoupling of anabolism and catabolism [49], 
191 the prevention of accumulation of phosphorylated intermediates [6,21], virulence [3],

192 programmed cell death [22,37], and oxidative stress [58]. Therefore, the reduction in the

193 abundance of transcripts encoding cellular glyoxalases suggests that tuning of methylglyoxal

194 intracellular content in $\mathrm{H}_{2} \mathrm{O}_{2}$ stressed cells is important in E. faecalis oxidative stress

195 adaptation.

196 3.3.2. Transport

197 Iron uptake

198 Table 2 and Table 4 show a notable increase in mRNA encoded by 10 genes belonging to 4

199 putative operons, with functions related to iron transport. Iron is an essential element for most

200 microbes, since many enzymes use iron as a cofactor [1]. During pathogenic processes, iron

201 acquisition systems are often found to be highly expressed to compensate for low iron

202 availability within the host [47]. Interestingly, the greatest increase in mRNA encoding an 203 iron transporter in our study (ef3082-3085), was also shown to be affected by growth in blood

204 [53]. Conversely, the expression of the $m n t H$ gene (ef1057), that was recently shown to be 205 strongly repressed in response to iron excess in E. faecalis OG1-RF [29], was not modified in 206 our experimental conditions. There is also an intimate relationship between iron metabolism 207 and oxidative stress. First, through the Fenton/Haber-Weiss reaction, iron can promote the 208 formation of hydroxyl radicals, which indiscriminately damage all cellular components [9,51].

209 Second, iron acts as a co-factor for several enzymes, including some involved in oxidative 210 stress defence, such as KatA or Dps.

211 The induction by $\mathrm{H}_{2} \mathrm{O}_{2}$ of genes with functions in iron uptake was also observed in Bacillus 212 subtilis, and could reflect an adaptive response to iron limitation [33]. Taken together, our 213 results suggest that $\mathrm{H}_{2} \mathrm{O}_{2}$-stressed cells encounter an intracellular iron limitation that could 214 result from iron recruitment by certain oxidative defence proteins (e.g. catalase), necessitating 215 increased transport capacity to meet the competing intracellular iron needs. 
Stress related transporters

217 We observed in Table 2 and Table 3 that hydrogen peroxide resulted in increased abundance 218 of transcripts of $k d p A, k d p B, k d p C, k d p D$, encoding the high affinity ABC potassium transport system Kdp, and ef0575-ef0576 (cationic $\mathrm{ABC}$ transporter). At the same time, $\mathrm{H}_{2} \mathrm{O}_{2}$ exposure resulted in reduced levels of cadA (cadmium-translocating P-type ATPase), ef0986 (cation 221 transporter) and $n h a C\left(\mathrm{Na}^{+} / \mathrm{H}^{+}\right.$antiporter) mRNA. Select changes were verified by RT-qPCR 222 (Table 4). All bacterial $k d p$ operons investigated so far are repressed during growth in media of high external $\mathrm{K}^{+}$concentration $\left(\left[\mathrm{K}^{+}\right] \mathrm{e}\right)[2]$. Increased abundance of mRNA encoding the $k d p$ operon under our experimental condition, suggests that $\mathrm{H}_{2} \mathrm{O}_{2}$ led to an intracellular $\mathrm{K}^{+}$ limitation. Thus, the Kdp-ATPase is an efficient $\mathrm{K}^{+}$scavenging system that isexpressed when other $\mathrm{K}^{+}$transporters cannot support cellular requirement for $\mathrm{K}^{+}$, which not only plays a vital role in bacterial osmotic adaptation $[10,40]$ but is also important for $\mathrm{pH}$ regulation, gene expression and activation of cellular enzymes [42]. The most notable deficiency observed in the nhaC deletion strain of Bacillus firmus was its poor growth at $\mathrm{pH} 7.5$ and $\mathrm{Na}^{+}$ concentrations up to $25 \mathrm{mM}$ [20], suggesting its contribution in osmotic stress. The cadmium

231 cation is toxic to most microorganisms, probably by binding to essential respiratory proteins 232 [52] and through oxidative damage by production of reactive oxygen species [48]. One of the 233 best-characterized bacterial cadmium resistance mechanisms is determined by the 234 cadmium-transporting ATPase encoded by cadA found in Staphylococcus aureus [36] and 235 Listeria monocytogenes [27,28]. Various stresses ( $\mathrm{NaCl}$, heat, ethanol, acidity and alkalinity) 236 induced weak or strong $\mathrm{H}_{2} \mathrm{O}_{2}$ cross-protection in E. faecalis ATCC19433 [12]. Combined 237 results suggest that the pre-treatment of $\mathrm{H}_{2} \mathrm{O}_{2}$ could increase the bacterial osmotolerance and 238 resistance to antibiotic, and decrease the bacterial resistance to cadmium.

\subsubsection{Genes involved in the adaptation to oxidative stress}

240 Expression of other genes clearly involved in the adaptation to oxidative stress did not 
significantly change in GM17 medium supplemented with $1.75 \mathrm{mM} \mathrm{H} \mathrm{H}_{2} \mathrm{O}_{2}$ (Table 6). These

242 genes may already be expressed at a high level in laboratory growth. Interestingly, although

243 not reaching the criteria used for significance in this study, the abundance of transcripts

244 encoding $m s r B$ (Peptide methionine-S- sulfoxide reductase [25]) was reduced 1.65 fold by

$245 \mathrm{H}_{2} \mathrm{O}_{2}$. The repression of $m s r B$ in $2.5 \mathrm{mM} \mathrm{H}_{2} \mathrm{O}_{2}$ adaptation for 30 minutes and the resistance of

$246 \Delta m s r B$ double crossing over mutant to the lethal challenge of $7 \mathrm{mM} \mathrm{H}_{2} \mathrm{O}_{2}$ for 6 hours

247 observed in E. faecalis, suggests that $\operatorname{msrB}$ contributes negatively to adaptation to oxidative

248 stress [61]. It therefore was not surprising that when E. faecalis is facing the oxidative stress

249 of $\mathrm{H}_{2} \mathrm{O}_{2}$, a reduction in transcripts for $m s r B$ was observed.

250 3.4. Concluding remarks

251 Global changes in the abundance of mRNA for all genes in exponentially growing E. faecalis 252 cells, cultured in the presence of a low dose $(1.75 \mathrm{mM})$ of $\mathrm{H}_{2} \mathrm{O}_{2}$, was measured. At this time 253 (4 h), E. faecalis had almost completely adapted as evinced by restoration of its growth rate 254 (Fig. 1). Analysis of changes in transcript abundance in response to this stress revealed that (i) 255 the expression of most of the well-known oxidative stress genes of E. faecalis was not 256 significantly altered, possibly because they already were highly expressed in rapid growth in 257 laboratory conditions, or because they may be regulated post-transcriptionally to minimize the 258 time delay associated with response to a potentially lethal condition. Among the responses we 259 did observe, we found that under $\mathrm{H}_{2} \mathrm{O}_{2}$ stress, E. faecalis restricted the metabolism of 260 ethanolamine, and limited the metabolism of methylglyoxal, but increased its use of transport 261 systems to satisfy the specific demand for essential metal ions, such as iron. Concomitantly, 262 we observed decreased expression of some genes known to contribute to adaptation to other stresses (e.g. nhaC, $\operatorname{cadA}$ ). Future work will aim at determining whether and how (i)

264 metabolic changes in ethanolamine and methylglyoxal metabolism, and iron transport, 265 impact the adaptation of E. faecalis to these specific conditions; and (ii) how changes in 
266 expression of genes clearly involved in the adaptation to other stresses affect cross adaptation.

267 It will also be of importance to determine the role of the 60 genes encoding hypothetical 268 proteins that were shown to be deregulated in these conditions.

\section{Acknowledgements}

271 X.Y. was the recipient of a doctoral fellowship from INRA (MICA Department) and the

272 Conseil Régional de Basse-Normandie, France. Microarray design, development and 273 production was supported by NIH grant AI083214 "Harvard-wide program on antibiotic 274 resistance." The authors deeply thank Annick Blandin and Marie-Jeanne Pigny for expert 275 technical assistance, and Christelle Thibault from IGBMC, Strasbourg (France), for DNA 276 chip hybridization. 


\section{References}

[1] Andrews SC, Robinson AK, Rodríguez-Quiñones F (2003) Bacterial iron homeostasis. FEMS Microbiol Rev 27:215-237.

[2] Ballal A, Basu B, Apte SK (2007) The Kdp-ATPase system and its regulation. J Biosci 32:559-568.

[3] Baskaran S, Prasanna Rajan D, Balasubramanian KA (1989) Formation of methylglyoxal by bacteria isolated from human faeces. J Med Microbiol 28:211-215.

[4] Booth IR, Ferguson G, Miller S, Li C, Gunasekera B, Kinghorn S (2003) Bacterial production of methylglyoxal: a survival strategy or death by misadventure? Biochem Soc Trans 31:1406-1408.

[5] Bourgogne A, Hilsenbeck SG, Dunny GM, Murray BE (2006) Comparison of OG1RF and an isogenic $f s r B$ deletion mutant by transcriptional analysis: the Fsr system of Enterococcus faecalis is more than the activator of gelatinase and serine protease. $\mathbf{J}$ Bacteriol 188:2875-2884.

[6] Burke RM, Tempest DW (1990) Growth of Bacillus stearothermophilus on glycerol in chemostat culture: expression of an unusual phenotype. J Gen Microbiol 136:1381-1385.

[7] Collier PD, Cromie DDO, Davies AP (1991) Mechanism of formation of chloropropanols present in protein hydrolysates. J Am Oil Chem Soc 68:785-790.

[8] Cooper RA (1984) Metabolism of methylglyoxal in microorganisms. Annu Rev Microbiol 38:49-68.

[9] Cornelis P, Wei Q, Andrews SC, Vinckx T (2011) Iron homeostasis and management of oxidative stress response in bacteria. Metallomics 3:540-549.

[10] Epstein W (1986) Osmoregulation by potassium transport in Escherichia coli. FEMS Microbiol Lett 39:73-78.

[11] Ferguson GP, Tötemeyer S, MacLean MJ, Booth IR (1998) Methylglyoxal production in bacteria: suicide or survival? Arch Microbiol 170:209-218.

[12] Flahaut S, Laplace JM, Frère J, Auffray Y (1998) The oxidative stress response in Enterococcus faecalis: relationship between $\mathrm{H}_{2} \mathrm{O}_{2}$ tolerance and $\mathrm{H}_{2} \mathrm{O}_{2}$ stress proteins. Lett Appl Microbiol 26:259-264.

[13] Franceschini A, Szklarczyk D, Frankild S, Kuhn M, Simonovic M, Roth A, et al. (2013) STRING v9.1: protein-protein interaction networks, with increased coverage and integration. Nucleic Acids Res 41:D808-815.

[14] Frankenberg L, Brugna M, Hederstedt L (2002) Enterococcus faecalis Heme-Dependent Catalase. J Bacteriol 184:6351-6356. 
[15] Gentleman RC, Carey VJ, Bates DM, Bolstad B, Dettling M, Dudoit S, et al. (2004) Bioconductor: open software development for computational biology and bioinformatics. Genome Biol 5:R80.

[16] Giard JC, Riboulet E, Verneuil N, Sanguinetti M, Auffray Y, Hartke A (2006) Characterization of Ers, a PrfA-like regulator of Enterococcus faecalis. FEMS Immunol Med Microbiol 46:410-418.

[17] Giraffa G (2003) Functionality of enterococci in dairy products. Int J Food Microbiol $88: 215-222$.

[18] Hugas M, Garriga M, Aymerich MT (2003) Functionality of enterococci in meat products. Int J Food Microbiol 88:223-233.

[19] Inoue Y, Kimura A (1995) Methylglyoxal and regulation of its metabolism in microorganisms. Adv Microb Physiol 37:177-227.

[20] Ito M, Guffanti AA, Zemsky J, Ivey DM, Krulwich TA (1997) Role of the nhaC-encoded $\mathrm{Na}+/ \mathrm{H}+$ antiporter of alkaliphilic Bacillus firmus OF4. J Bacteriol 179:3851-3857.

[21] Kadner RJ, Murphy GP, Stephens CM (1992) Two mechanisms for growth inhibition by elevated transport of sugar phosphates in Escherichia coli. J Gen Microbiol 138:2007-2014.

[22] Kang Y, Edwards LG, Thornalley PJ (1996) Effect of methylglyoxal on human leukaemia 60 cell growth: modification of DNA G1 growth arrest and induction of apoptosis. Leuk Res 20:397-405.

[23] Klebanoff SJ (1980) Oxygen metabolism and the toxic properties of phagocytes. Ann Intern Med 93:480-489.

[24] Kofoid E, Rappleye C, Stojiljkovic I, Roth J (1999) The 17-gene ethanolamine (eut) operon of Salmonella typhimurium encodes five homologues of carboxysome shell proteins. J Bacteriol 181:5317-5329.

[25] Laplace JM, Hartke A, Giard JC, Auffray Y (2000) Cloning, characterization and expression of an Enterococcus faecalis gene responsive to heavy metals. Appl Microbiol Biotechnol 53:685-689.

[26] Lawhon SD, Frye JG, Suyemoto M, Porwollik S, McClelland M, Altier C (2003) Global regulation by CsrA in Salmonella typhimurium. Mol Microbiol 48:1633-1645.

[27] Lebrun M, Audurier A, Cossart P (1994) Plasmid-borne cadmium resistance genes in Listeria monocytogenes are present on Tn5422, a novel transposon closely related to Tn917. J Bacteriol 176:3049-3061.

[28] Lebrun M, Loulergue J, Chaslus-Dancla E, Audurier A (1992) Plasmids in Listeria monocytogenes in relation to cadmium resistance. Appl Environ Microbiol 58:3183-3186. 
[29] López G, Latorre M, Reyes-Jara A, Cambiazo V, González M (2012) Transcriptomic response of Enterococcus faecalis to iron excess. Biometals 25:737-747.

352

[30] Mercenier A, Pavan S, Pot B (2003) Probiotics as biotherapeutic agents: present knowledge and future prospects. Curr Pharm Des 9:175-191.

[31] Misra K, Banerjee AB, Ray S, Ray M (1995) Glyoxalase III from Escherichia coli: a single novel enzyme for the conversion of methylglyoxal into D-lactate without reduced glutathione. Biochem J 305:999-1003.

[32] Misra K, Banerjee AB, Ray S, Ray M (1996) Reduction of methylglyoxal in Escherichia coli $\mathrm{K} 12$ by an aldehyde reductase and alcohol dehydrogenase. Mol Cell Biochem 156:117-124.

[33] Mostertz J, Scharf C, Hecker M, Homuth G (2004) Transcriptome and proteome analysis of Bacillus subtilis gene expression in response to superoxide and peroxide stress. Microbiology 150:497-512.

[34] Nathan CF (1983) Mechanisms of macrophage antimicrobial activity. Trans R Soc Trop Med Hyg 77:620-630.

[35] Noskin GA, Till M, Patterson BK, Clarke JT, Warren JR (1991) High-level gentamicin resistance in Enterococcus faecalis bacteremia. J Infect Dis 164:1212-1215.

[36] Nucifora G, Chu L, Misra TK, Silver S (1989) Cadmium resistance from Staphylococcus aureus plasmid pI258 cadA gene results from a cadmium-efflux ATPase. Proc Natl Acad Sci USA 86:3544-3548.

[37] Okado A, Kawasaki Y, Hasuike Y, Takahashi M, Teshima T, Fujii J, et al. (1996) Induction of apoptotic cell death by methylglyoxal and 3-deoxyglucosone in macrophage-derived cell lines. Biochem Biophys Res Commun 225:219-224.

[38] del Papa MF, Perego M (2008) Ethanolamine activates a sensor histidine kinase regulating its utilization in Enterococcus faecalis. J Bacteriol 190:7147-7156.

[39] Paulsen IT, Banerjei L, Myers GSA, Nelson KE, Seshadri R, Read TD, et al. (2003) Role of mobile DNA in the evolution of vancomycin-resistant Enterococcus faecalis. Science 299:2071-2074.

[40] Pichereau V, Hartke A, Auffray Y (2000) Starvation and osmotic stress induced multiresistances. Influence of extracellular compounds. Int J Food Microbiol 55:19-25.

[41] Poyart C, Quesnes G, Trieu-Cuot P (2000) Sequencing the gene encoding manganese-dependent superoxide dismutase for rapid species identification of enterococci. J Clin Microbiol 38:415-418.

[42] Prince WS, Villarejo MR (1990) Osmotic control of proU transcription is mediated through direct action of potassium glutamate on the transcription complex. J Biol Chem 265:17673-17679. 
[43] Rincé A, Giard JC, Pichereau V, Flahaut S, Auffray Y (2001) Identification and characterization of gsp65, an organic hydroperoxide resistance (ohr) gene encoding a general stress protein in Enterococcus faecalis. J Bacteriol 183:1482-1488.

[44] Ross RP, Claiborne A (1991) Cloning, sequence and overexpression of NADH peroxidase from Streptococcus faecalis 10C1. Structural relationship with the flavoprotein disulfide reductases. J Mol Biol 221:857-871.

[45] Sahm DF, Kissinger J, Gilmore MS, Murray PR, Mulder R, Solliday J, et al. (1989) In vitro susceptibility studies of vancomycin-resistant Enterococcus faecalis. Antimicrob Agents Chemother 33:1588-1591.

395

396

397

398

399

400

401

402

403

404

405

406

407

408

409

[46] Schaberg DR, Culver DH, Gaynes RP (1991) Major trends in the microbial etiology of nosocomial infection. Am J Med 91:72S-75S.

[47] Skaar EP (2010) The battle for iron between bacterial pathogens and their vertebrate hosts. PLoS Pathog 6:e1000949.

[48] Stohs SJ, Bagchi D (1995) Oxidative mechanisms in the toxicity of metal ions. Free Radic Biol Med 18:321-336.

[49] Tempest DW, Neijssel OM (1984) The status of YATP and maintenance energy as biologically interpretable phenomena. Annu Rev Microbiol 38:459-486.

[50] Thomas EL, Lehrer RI, Rest RF (1988) Human neutrophil antimicrobial activity. Rev Infect Dis 10 Suppl:S450-456.

[51] Touati D (2000) Iron and oxidative stress in bacteria. Arch Biochem Biophys 373:1-6.

[52] Vallee BL, Ulmer DD (1972) Biochemical effects of mercury, cadmium, and lead. Annu Rev Biochem 41:91-128.

[53] Vebø HC, Snipen L, Nes IF, Brede DA (2009) The transcriptome of the nosocomial pathogen Enterococcus faecalis V583 reveals adaptive responses to growth in blood. PLoS One 4:e7660.

[54] Verneuil N, Le Breton Y, Hartke A, Auffray Y, Giard JC (2004) Identification of a new oxidative stress transcriptional regulator in Enterococcus faecalis. Lait 84:69-76.

[55] Verneuil N, Rincé A, Sanguinetti M, Auffray Y, Hartke A, Giard JC (2005) Implication of hypR in the virulence and oxidative stress response of Enterococcus faecalis. FEMS Microbiol Lett 252:137-141.

[56] Verneuil N, Rincé A, Sanguinetti M, Posteraro B, Fadda G, Auffray Y, et al. (2005) Contribution of a PerR-like regulator to the oxidative-stress response and virulence of Enterococcus faecalis., Microbiology 151:3997-4004.

[57] Verneuil N, Sanguinetti M, Le Breton Y, Posteraro B, Fadda G, Auffray Y, et al. (2004) Effects of the Enterococcus faecalis hypR gene encoding a new transcriptional regulator 
on oxidative stress response and intracellular survival within macrophages. Infect Immun 72:4424-4431.

423

424

425

426

[58] Wu L, Juurlink BHJ (2002) Increased methylglyoxal and oxidative stress in hypertensive rat vascular smooth muscle cells. Hypertension 39:809-814.

[59] Yan X, Zhao C, Budin-Verneuil A, Hartke A, Rincé A, Gilmore MS, Auffray Y, Pichereau V (2009) The (p)ppGpp synthetase RelA contributes to stress adaptation and virulence in Enterococcus faecalis V583. Microbiology 155:3226-3237.

[60] Yan X, Budin-Verneuil A, Auffray Y, Pichereau V (2014) Proteome phenotyping of $\Delta$ relA mutants in Enterococcus faecalis V583. Can J Microbiol 60:525-531.

[61] Zhao C, Hartke A, La Sorda M, Posteraro B, Laplace JM, Auffray Y, et al. (2010) Role of methionine sulfoxide reductases A and B of Enterococcus faecalis in oxidative stress and virulence. Infect Immun 78:3889-3897. 


\section{Legends to figures}

435

436 Fig. 1. Growth of V583 ery ${ }^{\mathrm{S}}$ with shaking in GM17 medium or supplemented with $1.5 \mathrm{mM}$,

$4371.75 \mathrm{mM}$ and $2 \mathrm{mM} \mathrm{H}_{2} \mathrm{O}_{2}$. The arrows indicate the time at which RNA was extracted.

438

439 Fig. 2. Functional classification of genes with statistically significant increases ( $\square$ ) and

440 decreases ( $\square$ ) in mRNA level upon $4 \mathrm{~h}$ exposure to hydrogen peroxide (total of 213 genes).

441 The total number of genes associated with increased/decreased mRNA abundance as the

442 result of $\mathrm{H}_{2} \mathrm{O}_{2}$ exposure in each functional class is shown.

443

444 Fig. 3. Network analysis of genes shown to be associated with significant transcript changes

445 (built using STRING v9.1 [13]).

446 
447 Table 1. Oligonucleotide primers used for real-time quantitative PCR in this study.

\begin{tabular}{ll}
\hline 0188L: TCGCAGCTTGTGGTAATACG & 0188R: ACTCGCAATAATCCGTTTGG \\
0191L: GGAACACCGCAAGAAGTGAT & 0191R: GCCGCTGTGTCTGACTATGA \\
0475L: TCGAATTGCGCTGACAGATA & 0475R: TAGCGCGTTCTCCAACTTTT \\
0567L: CGCTATGCACTGAATGTGCT & 0567R: ACCTCCCGGTAAAAAGTGCT \\
0570L: GCTGGTGTTGGGAAAACCTA & 0570R: GGACGATCATGAGGTTCGAT \\
0575L: AGGCTTTGGAAAAGGTCGAT & 0575R: AAATCCGCATTTTGAGCAAG \\
0630L: AGTCAACCACGTGGGGATTA & 0630R: TTCCACCAATTTCATCACGA \\
0666L: TCTTGAGCAAGCGGGTATCT & 0666R: AGCGCCATTTGCGTATTATC \\
1120L: TTAAAGTGATGGGCGTTTCC & 1120R: TGCGAAGGATAAGCAGAAGC \\
1617L: ACCCGAAATCGACGTAACAG & 1617R: GGCGCGGACTTTCTTCTAA \\
1620L: TGAAGGTAAGCCGGTATTGG & 1620R: GTCCACGTTTCCTGAATCG \\
1621L: CAACCTGGACAGTTCGTTTGT & 1621R: TGTGATTCGCTACGTTCAGG \\
1624L: AAATTGGCACCGATTATTGC & 1624R: ATTGTATGACCCGCACCTTC \\
1627L: CACGTCACTGAAACGACAGAA & 1627R: CAGGATCTACGGCATTTTTCA \\
1629L: ATCCATCGCTGGTTCAGAAA & 1629R: AGCTGCTTGACCACTGTGAA \\
1633L: TTAGGCGCACTGGGTTATTT & 1633R: TAACAGCTGCGTTTGTTGC \\
1635L: CAGGGATGGCGTTTAATGTT & 1635R: TTGCATTCATTCGTCCATGT \\
1638L: ATAAAACACAGGCGGTGGAA & 1638R: GCCGCTGTGACGTTTAATG \\
1669L: GCCCAAGTCGTTTTGGTAGA & 1669R: TGATTTACGATCCGCTAGGC \\
3085L: AACCGATAGTGCAAGGTTGG & 3085R: CCGCTTAGCGCAAAAATAAA \\
\hline
\end{tabular}


450 Table 2. Genes of Enterococcus faecalis $\mathrm{V} 583$ ery $^{\mathrm{S}}$ associated with increased transcript

451 abundance as the result of exposure to $\mathrm{H}_{2} \mathrm{O}_{2}$.

\begin{tabular}{llrc}
\hline Locus & Descriptions (Gene symbol) & M* $^{*}$ SD \\
\hline Biosynthesis and metabolism & & \\
EF0693 & 1-phosphofructokinase $($ fruK-1) & 1.1 & 0.3 \\
EF1222 & adenine deaminase (ade) & 1.4 & 0.2 \\
EF1511 & & 1.1 & 0.4 \\
& mandelate racemase/muconate lactonizing enzyme family protein & 1.1 & 0.1
\end{tabular}

Transport and binding protein

EF0188 iron compound ABC transporter, substrate-binding protein $2.0 \quad 0.6$

EF0191 ferrichrome ABC transporter, ATP-binding protein $1.1 \quad 0.3$

EF0192 ferrichrome ABC transporter, permease protein $1.0 \quad 0.1$

EF0193 ferrichrome ABC transporter, permease protein $(f h u G) \quad 1.0 \quad 0.3$

EF0475 ferrous iron transport protein $\mathrm{A}(f e o A) \quad 1.3 \quad 0.0$

EF0476 ferrous iron transport protein B $(f e o B) \quad 1.6 \quad 0.1$

EF0567 potassium-transporting ATPase, subunit A $(k d p A) \quad 1.2 \quad 0.4$

EF0568 potassium-transporting ATPase, subunit B $(k d p B) \quad 1.2 \quad 0.4$

EF0569 potassium-transporting ATPase, subunit $\mathrm{C}(k d p C) \quad 1.2 \quad 0.1$

EF0575 cationic ABC transporter, ATP-binding protein $\quad 1.0 \quad 0.2$

EF0576 cation ABC transporter, permease protein $1.1 \quad 0.1$

EF0694 PTS system, fructose-specific family, IIBC components 0.6

EF1053 ABC transporter, ATP-binding protein $1.0 \quad 0.5$

EF1117 amino acid ABC transporter, permease protein $\quad 2.2 \quad 0.4$

EF1118 amino acid ABC transporter, permease protein $2.3 \quad 0.2$

EF1119 amino acid ABC transporter, amino acid-binding protein $\quad 2.0 \quad 0.1$

EF1120 amino acid ABC transporter, ATP-binding protein $\quad 1.8 \quad 0.1$

EF1220 spermidine/putrescine ABC transporter, ATP-binding protein $\quad 1.0 \quad 0.2$

EF3082 iron compound $\mathrm{ABC}$ transporter, substrate-binding protein $3.1 \quad 0.8$

EF3083 iron compound ABC transporter, ATP-binding protein $3.2 \quad 0.6$

EF3084 iron compound $\mathrm{ABC}$ transporter, permease protein $3.2 \quad 0.7$

EF3085 iron compound $\mathrm{ABC}$ transporter, permease protein $3.3 \quad 0.6$

Regulation and signal

EF0570 sensor histidine kinase $(k d p D) \quad 0.1$

EF0578 helix-turn-helix protein, iron-dependent repressor family $1.3 \quad 0.1$

Cell envelope and cell division

EF0887 glycosyl transferase, group 2 family protein $1.5 \quad 0.1$

EF3314 cell wall surface anchor family protein $1.5 \quad 0.1$

Stress and Virulence

EF2068 multidrug resistance protein, putative $1.2 \quad 0.1$

Unknown

EF0477 hypothetical protein $1.7 \quad 0.8$

EF0886 hypothetical protein $\quad 1.4 \quad 0.2$

EF0888 conserved hypothetical protein $1.0 \quad 0.1$

EF0889 conserved hypothetical protein $1.2 \quad 0.4$

EF1223 chlorohydrolase family protein 0.6

EF1512 conserved hypothetical protein $1.1 \quad 0.3$

EF1808 agaS protein $1.1 \quad 0.4$

EF2067 conserved hypothetical protein TIGR00481 0.0

*M is the mean Log2(fold ratio); SD is the standard deviation. 
454 Table 3. Genes of Enterococcus faecalis V583 ery ${ }^{\mathrm{S}}$ associated with transcript reductions as 455 the result of exposure to $\mathrm{H}_{2} \mathrm{O}_{2}$.

\begin{tabular}{|c|c|c|c|}
\hline Locus & Descriptions (Gene symbol) & M* & SD \\
\hline \multicolumn{4}{|c|}{ Biosynthesis and metabolism } \\
\hline EF0098 & & -2.4 & 0.2 \\
\hline \multirow{3}{*}{ EF0099 } & L-serine dehydratase, iron-sulfur-dependent, beta subunit (sdhB-1) & & \\
\hline & & -2.7 & 0.6 \\
\hline & L-serine dehydratase, iron-sulfur-dependent, alpha subunit ( $\operatorname{sdh} A-1)$ & & \\
\hline EF0630 & glyoxalase family protein & -1.0 & 0.1 \\
\hline EF0867 & glyoxalase family protein & -1.2 & 0.1 \\
\hline EF1358 & glycerol dehydrogenase, putative & -1.6 & 0.5 \\
\hline EF1617 & conserved hypothetical protein (EutQ) & -2.6 & 0.5 \\
\hline EF1618 & ethanolamine utilization protein $(E u t H)$ & -2.7 & 0.6 \\
\hline EF1619 & carbon dioxide concentrating mechanism protein $\mathrm{CcmL}$, putative (EutN) & -2.8 & 0.3 \\
\hline EF1620 & hypothetical protein $(E u t X)$ & -2.9 & 0.5 \\
\hline EF1621 & conserved hypothetical protein (EutY) & -2.8 & 0.5 \\
\hline EF1622 & conserved domain protein $(E u t Z)$ & -3.0 & 0.3 \\
\hline EF1623 & microcompartment protein $(E u t K)$ & -2.6 & 0.4 \\
\hline EF1624 & aldehyde dehydrogenase, putative (EutE) & -3.1 & 0.1 \\
\hline EF1625 & microcompartment protein family (EutM) & -3.0 & 0.0 \\
\hline EF1626 & ethanolamine utilization protein $(E u t L)$ & -3.1 & 0.1 \\
\hline EF1627 & ethanolamine ammonia-lyase small subunit (EutC) & -3.3 & 0.1 \\
\hline EF1629 & ethanolamine ammonia-lyase large subunit (EutB) & -3.4 & 0.1 \\
\hline EF1632 & sensor histidine kinase $(H K)$ & -1.1 & 0.1 \\
\hline EF1633 & response regulator $(R R)$ & -1.1 & 0.1 \\
\hline EF1634 & propanediol utilization protein PduU (EutS) & -1.1 & 0.1 \\
\hline EF1635 & propanol dehydrogenase PduQ, putative $(E u t G)$ & -2.1 & 0.0 \\
\hline EF1637 & ATP:cob(I)alamin adenosyltransferase, putative (EutT) & -1.7 & 0.0 \\
\hline EF1638 & propanediol utilization protein PduV (eutP) & -1.3 & 0.1 \\
\hline EF1669 & glyoxylase family protein & -1.0 & \\
\hline
\end{tabular}

Protein biosynthesis and fate

$\begin{array}{ll}\text { EF0100 } & \text { seryl-tRNA synthetase }(\operatorname{ser} S-1) \\ \text { EF0650 } & \text { lipoate-protein ligase A (lplA-1) }\end{array}$

DNA metabolism

EF2114 adenine methyltransferase, putative

Transport and binding protein

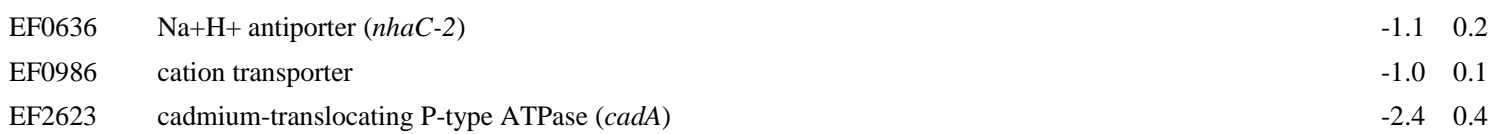

Regulation and signal

EF0097 regulatory protein pfoR, putative

EF0110 transcriptional regulator, ArsR family

EF0143 transcriptional regulator, CroCI family

EF0923 transcriptional regulator, LysR family

EF1668 transcriptional regulator, MarR family

$-1.4 \quad 0.1$

EF2141 transcriptional regulator, CroCI family

Cell envelope and cell division

\section{EF0139 FtsKSpoIIIE family protein}

EF0153 cell wall surface anchor family protein 
Stress and virulence

EF0149 aggregation substance, putative

Mobile and extrachromosomal element functions

EF0158 conjugal transfer protein, putative

$\begin{array}{ll}-1.3 & 0.4\end{array}$

EF2096 tail protein

\begin{tabular}{|c|c|}
\hline Unknown & \\
\hline EF0083 & hypothetical protein \\
\hline EF0109 & ThiJPfpI family protein \\
\hline EF0131 & conserved domain protein \\
\hline EF0132 & hypothetical protein \\
\hline EF0134 & hypothetical protein \\
\hline EF0135 & conserved hypothetical protein \\
\hline EF0136 & hypothetical protein \\
\hline EF0138 & conserved domain protein \\
\hline EF0142 & conserved hypothetical protein \\
\hline EF0144 & conserved domain protein \\
\hline EF0151 & hypothetical protein \\
\hline EF0152 & hypothetical protein \\
\hline EF0154 & conserved hypothetical protein \\
\hline EF0155 & conserved hypothetical protein \\
\hline EF0415 & conserved hypothetical protein \\
\hline EF0519 & hypothetical protein \\
\hline EF0971 & conserved hypothetical protein \\
\hline EF1327 & BadFBadGBcrABcrD ATPase family protein \\
\hline EF1359 & conserved hypothetical protein \\
\hline EF1360 & dihydroxyacetone kinase family protein \\
\hline EF1361 & dihydroxyacetone kinase family protein \\
\hline EF1362 & conserved domain protein \\
\hline EF2014 & coenzyme F420 hydrogenase domain protein \\
\hline EF2065 & conserved hypothetical protein \\
\hline EF2094 & hypothetical protein \\
\hline EF2095 & hypothetical protein \\
\hline EF2097 & hypothetical protein \\
\hline EF2098 & hypothetical protein \\
\hline EF2099 & hypothetical protein \\
\hline $\mathrm{EF} 2100$ & hypothetical protein \\
\hline EF2101 & hypothetical protein \\
\hline EF2102 & hypothetical protein \\
\hline EF2103 & hypothetical protein \\
\hline EF2104 & hypothetical protein \\
\hline EF2105 & hypothetical protein \\
\hline EF2106 & conserved domain protein \\
\hline $\mathrm{EF} 2107$ & hypothetical protein \\
\hline EF2108 & hypothetical protein \\
\hline EF2109 & conserved domain protein \\
\hline $\mathrm{EF} 2110$ & hypothetical protein \\
\hline $\mathrm{EF} 2111$ & hypothetical protein \\
\hline EF2112 & hypothetical protein \\
\hline EF2113 & conserved hypothetical protein \\
\hline EF2120 & conserved hypothetical protein \\
\hline EF2125 & hypothetical protein \\
\hline EF2127 & hypothetical protein \\
\hline
\end{tabular}

$-1.10 .6$

$-1.10 .1$

$-1.5 \quad 0.2$

$-1.4 \quad 0.2$

$-1.10 .1$

$-1.0 \quad 0.1$

$-1.10 .1$

$\begin{array}{ll}-1.1 & 0.0\end{array}$

$\begin{array}{ll}-1.0 & 0.3\end{array}$

$\begin{array}{ll}-1.2 & 0.3\end{array}$

$\begin{array}{ll}-1.2 & 0.4\end{array}$

$-1.0 \quad 0.6$

$\begin{array}{ll}-1.7 & 0.1\end{array}$

$\begin{array}{ll}-1.6 & 0.4\end{array}$

$\begin{array}{ll}-1.4 & 0.4\end{array}$

$\begin{array}{ll}-1.0 & 0.1\end{array}$

$\begin{array}{ll}-1.1 & 0.1\end{array}$

$\begin{array}{ll}-1.4 & 0.5\end{array}$

$\begin{array}{ll}-1.3 & 0.3\end{array}$

$\begin{array}{ll}-1.2 & 0.4\end{array}$

$\begin{array}{ll}-1.4 & 0.2\end{array}$

$\begin{array}{ll}-1.1 & 0.1\end{array}$

$\begin{array}{ll}-1.0 & 0.1\end{array}$

$\begin{array}{ll}-1.0 & 0.1\end{array}$

$\begin{array}{ll}-1.1 & 0.1\end{array}$

$\begin{array}{ll}-1.1 & 0.3\end{array}$

$\begin{array}{ll}-1.5 & 0.1\end{array}$

$\begin{array}{ll}-1.4 & 0.2\end{array}$

$-1.60 .1$

$\begin{array}{ll}-1.5 & 0.1\end{array}$

$\begin{array}{ll}-1.6 & 0.2\end{array}$

$\begin{array}{ll}-1.7 & 0.4\end{array}$

$\begin{array}{ll}-1.6 & 0.3\end{array}$

$\begin{array}{ll}-1.7 & 0.1\end{array}$

$\begin{array}{ll}-1.7 & 0.1\end{array}$

$-1.6 \quad 0.1$

$-1.7 \quad 0.1$

$\begin{array}{ll}-1.6 & 0.3\end{array}$

$\begin{array}{ll}-1.8 & 0.0\end{array}$

$-1.60 .0$

$\begin{array}{ll}-1.7 & 0.1\end{array}$

$\begin{array}{ll}-1.7 & 0.1\end{array}$

$\begin{array}{ll}-1.6 & 0.3\end{array}$

$-1.0 \quad 0.6$

$\begin{array}{ll}-1.0 & 0.3\end{array}$

$\begin{array}{ll}-1.0 & 0.2\end{array}$ 
EF213

hypothetical protein

$\begin{array}{ll}-1.0 & 0.3\end{array}$

EF2134

hypothetical protein

$-1.0 \quad 0.6$

EF2137

hypothetical protein

$\begin{array}{ll}-1.2 & 0.3\end{array}$

EF2140

conserved hypothetical protein

$\begin{array}{ll}-1.2 & 0.2\end{array}$

EF2606 conserved hypothetical protein

$-1.0 \quad 0.1$

EF2792 conserved hypothetical protein

$-1.0 \quad 0.0$

456

*M is the mean $\log 2$ (fold ratio); $\mathrm{SD}$ is the standard deviation.

457

458 
459 Table 4. Comparison of gene expression analyzed by real-time quantitative PCR and

460 Microarray.

\begin{tabular}{|c|c|c|c|}
\hline \multirow[t]{2}{*}{ Locus } & \multirow[t]{2}{*}{ (Gene symbol) Function } & \multicolumn{2}{|c|}{$\mathrm{H}_{2} \mathrm{O}_{2} / \mathrm{GM17}$} \\
\hline & & RT qPCR & Microarray \\
\hline ef0188 & iron compound $\mathrm{ABC}$ transporter, substrate-binding protein & $9.24 \pm 1.95$ & $3.94 \pm 1.20$ \\
\hline ef0191 & ferrichrome ABC transporter, ATP-binding protein & $3.33 \pm 0.70$ & $2.20 \pm 0.44$ \\
\hline ef0475 & (feoA) ferrous iron transport protein $\mathrm{A}$ & $3.16 \pm 0.99$ & $2.48 \pm 0.03$ \\
\hline ef0567 & (kdpA) potassium-transporting ATPase, subunit A & $2.72 \pm 1.27$ & $2.27 \pm 0.34$ \\
\hline ef0570 & (kdpD) sensor histidine kinase KdpD & $1.67 \pm 0.38$ & $1.99 \pm 0.12$ \\
\hline ef0575 & cationic $\mathrm{ABC}$ transporter, ATP-binding protein & $2.37 \pm 0.77$ & $1.92 \pm 0.25$ \\
\hline ef1120 & amino acid $\mathrm{ABC}$ transporter, $\mathrm{ATP}$-binding protein & $6.44 \pm 0.25$ & $3.52 \pm 0.03$ \\
\hline ef3085 & iron compound $\mathrm{ABC}$ transporter, permease protein & $18.1 \pm 7.18$ & $11.2 \pm 3.81$ \\
\hline ef0630 & glyoxalase family protein & $-3.92 \pm 0.91$ & $-2.00 \pm 0.14$ \\
\hline ef0867 & glyoxalase family protein & $-2.67 \pm 0.40$ & $-2.33 \pm 0.12$ \\
\hline ef1617 & (eutQ) conserved hypothetical protein & $-8.16 \pm 0.48$ & $-6.10 \pm 1.41$ \\
\hline ef1620 & (eutX) hypothetical protein & $-8.62 \pm 0.50$ & $-7.50 \pm 1.41$ \\
\hline ef1621 & (eutY) conserved hypothetical protein & $-3.41 \pm 0.95$ & $-7.00 \pm 1.41$ \\
\hline ef1624 & (eutE) aldehyde dehydrogenase, putative & $-9.18 \pm 0.60$ & $-8.60 \pm 1.07$ \\
\hline ef1627 & (eutC) ethanolamine ammonia-lyase small subunit & $-10.1 \pm 0.46$ & $-9.80 \pm 1.07$ \\
\hline ef1629 & (eutB) ethanolamine ammonia-lyase large subunit & $-7.76 \pm 0.45$ & $-10.6 \pm 1.07$ \\
\hline ef1633 & (RR17) response regulator & $-4.13 \pm 0.24$ & $-2.10 \pm 1.07$ \\
\hline ef1635 & (eutG) propanol dehydrogenase PduQ, putative & $-11.7 \pm 0.85$ & $-4.30 \pm 1.07$ \\
\hline ef1638 & (eutP) propanediol utilization protein PduV & $-2.82 \pm 0.26$ & $-2.50 \pm 1.07$ \\
\hline ef1669 & glyoxylase family protein & $-2.90 \pm 1.15$ & $-2.04 \pm 0.04$ \\
\hline
\end{tabular}

461 Values are given as means of the fold ratios \pm standard deviation (SD). 
463 Table 5. Expression of all the genes encoding glyoxalase family protein analyzed by 464 Microarray.

\begin{tabular}{llccccc}
\hline Locus & \multicolumn{1}{c}{ Function } & \multicolumn{2}{c}{ Level of gene expression } & \multicolumn{2}{c}{ Ratio } \\
\hline & & $\mathbf{G M 1 7}$ & $\mathbf{H}_{\mathbf{2}} \mathbf{O}_{\mathbf{2}}$ & $\mathbf{G M 1 7}$ & $\mathbf{H}_{\mathbf{2}} \mathbf{O}_{\mathbf{2}}$ & $\mathbf{H}_{\mathbf{2}} \mathbf{O}_{\mathbf{2}} / \mathbf{G M 1 7}$ \\
\hline ef0358 & glyoxalase family protein & 330.7 & 164.6 & 408.5 & 224.2 & $-1.92 \pm 0.10$ \\
ef0939 & methylglyoxal synthase & 1627.9 & 961 & 1806.1 & 909.7 & $-1.84 \pm 0.15$ \\
ef0630 & glyoxalase family protein & 1152.1 & 541.5 & 945.8 & 508.4 & $-2.00 \pm 0.14$ \\
ef0656 & glyoxalase family protein & 138.8 & 112.8 & 236.1 & 178.6 & $-1.28 \pm 0.04$ \\
ef0666 & glyoxalase family protein & 2717 & 1834 & 2571.2 & 1811.8 & $-1.45 \pm 0.03$ \\
ef0745 & glyoxalase family protein & 1003.8 & 974.3 & 1216.9 & 1119.1 & $-1.06 \pm 0.03$ \\
ef0867 & glyoxalase family protein & 253.7 & 114.8 & 292.7 & 119.8 & $-2.33 \pm 0.12$ \\
ef1669 & glyoxylase family protein & 260.3 & 125.4 & 314.8 & 161 & $-2.04 \pm 0.04$ \\
ef2591 & glyoxalase family protein & 3065.4 & 3012.3 & 3317.9 & 2821.4 & $-1.10 \pm 0.08$ \\
ef3092 & glyoxalase family protein & 1302.2 & 1004.4 & 1238.1 & 937.8 & $-1.31 \pm 0.01$ \\
\hline
\end{tabular}

465 Values are given as means of the fold ratios \pm standard deviation (SD). 

stress.

\begin{tabular}{|c|c|c|c|c|}
\hline \multirow[t]{2}{*}{ Locus } & \multirow[t]{2}{*}{ Protein (Gene) } & \multicolumn{2}{|c|}{ Expression of genes } & \multirow{2}{*}{$\begin{array}{c}\text { Ratio } \\
\mathrm{H}_{2} \mathrm{O}_{2} / \text { GM17 }\end{array}$} \\
\hline & & GM17 & $\mathbf{G M 1 7}+\mathrm{H}_{2} \mathrm{O}_{2}$ & \\
\hline \multicolumn{5}{|c|}{ Oxidative stress proteins } \\
\hline ef0453 & Organic hydroperoxide resistance protein $(\mathrm{ohr})$ & 3712.9 & 3449.6 & -1.07 \\
\hline ef0463 & Superoxide dismutase $(\operatorname{sod} A)$ & 4697.8 & 4342.7 & -1.08 \\
\hline ef0606 & DNA-binding protein $(d p s)$ & 384.5 & 370 & -1.04 \\
\hline ef1211 & NADH peroxidase $(n p r)$ & 4228.5 & 3577.3 & -1.18 \\
\hline ef1338 & Thioredoxine reductase $(\operatorname{tr} x)$ & 3292.4 & 2649.6 & -1.24 \\
\hline ef1405 & Thioredoxine reductase $(\operatorname{tr} x)$ & 1787.7 & 1772.6 & -1.01 \\
\hline ef1586 & NADH oxidase (nox) & 5842.3 & 6058.5 & 1.04 \\
\hline ef1597 & Catalase $($ katA $)$ & 2734.8 & 2806.2 & 1.03 \\
\hline ef1681 & Peptide methionine-S-sulfoxide reductase ( $m s r A)$ & 2144 & 1908.5 & 1.12 \\
\hline ef 2738 & Peroxiredoxine reductase $(a h p F)$ & 3974 & 3984.6 & 1.00 \\
\hline ef 2739 & Alkyl hydroperoxide reductase $(a h p C)$ & 4536.4 & 4583 & 1.01 \\
\hline ef3164 & Peptide methionine-S-sulfoxide reductase ( $m s r B)$ & 2449 & 1478.1 & -1.65 \\
\hline ef3233 & DNA-binding protein $(d p s)$ & 4553.2 & 4202.9 & -1.08 \\
\hline ef3270 & Glutathione reductase (gor) & 2707.7 & 2879.4 & 1.06 \\
\hline \multicolumn{5}{|c|}{ Oxidative stress related transcriptional regulators } \\
\hline ef1525 & (fur) & 2925.4 & 2397.8 & -1.22 \\
\hline ef1585 & (perR) & 2741.6 & 2304.2 & -1.19 \\
\hline ef 2063 & $(\operatorname{sox} S)$ & 1847.9 & 1969.6 & 1.07 \\
\hline ef 2417 & (zur) & 1017.1 & 804.2 & -1.26 \\
\hline ef 2958 & $($ hypR) & 245.1 & 256.9 & 1.05 \\
\hline
\end{tabular}


474

475

476

477

478

479

480

481

482

483

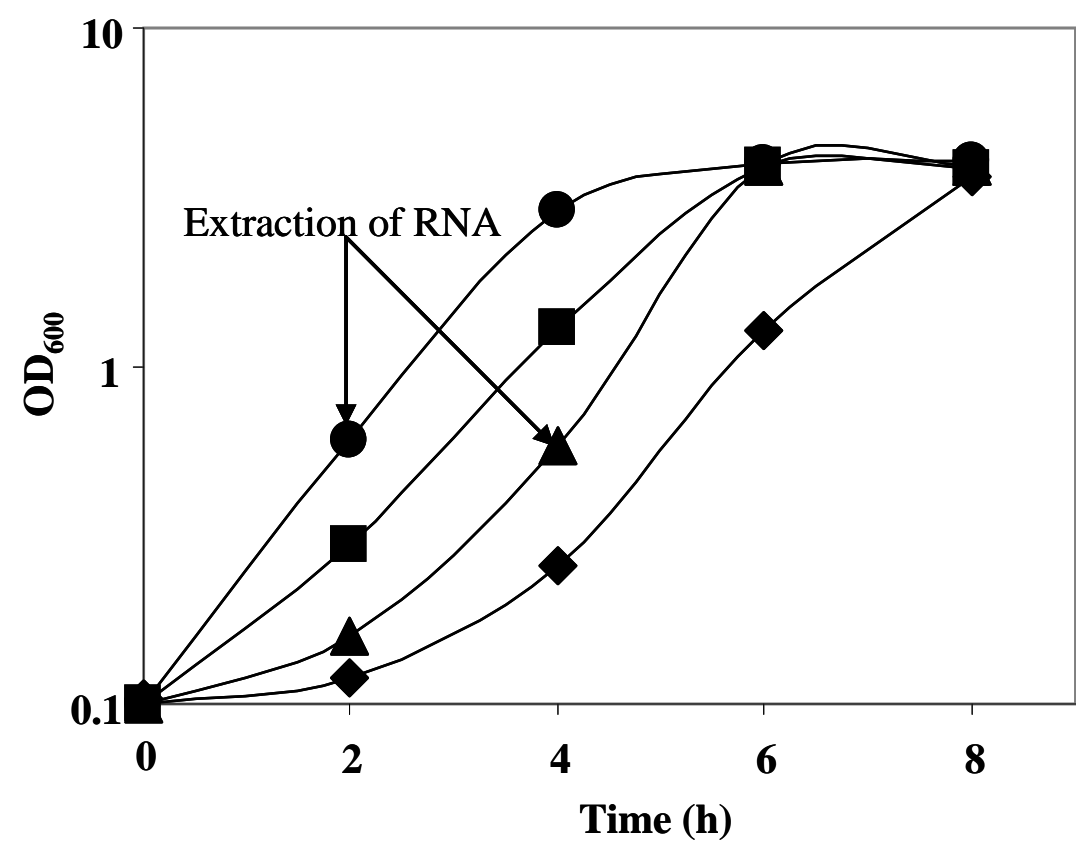

$\rightarrow$ GM17 $\rightarrow-1.5 \mathrm{mM} \mathrm{H}_{2} \mathrm{O}_{2}$

$-1.75 \mathrm{mM} \mathrm{H}_{2} \mathrm{O}_{2}$

$\multimap 2 \mathrm{mM} \mathrm{H}_{2} \mathrm{O}_{2}$

484

Fig. 1. 


Mobile and extrachromosomal
element functions
Stress and virulence

$\square$ Down-regulated

Up-regulated

493

494

Fig. 2. 


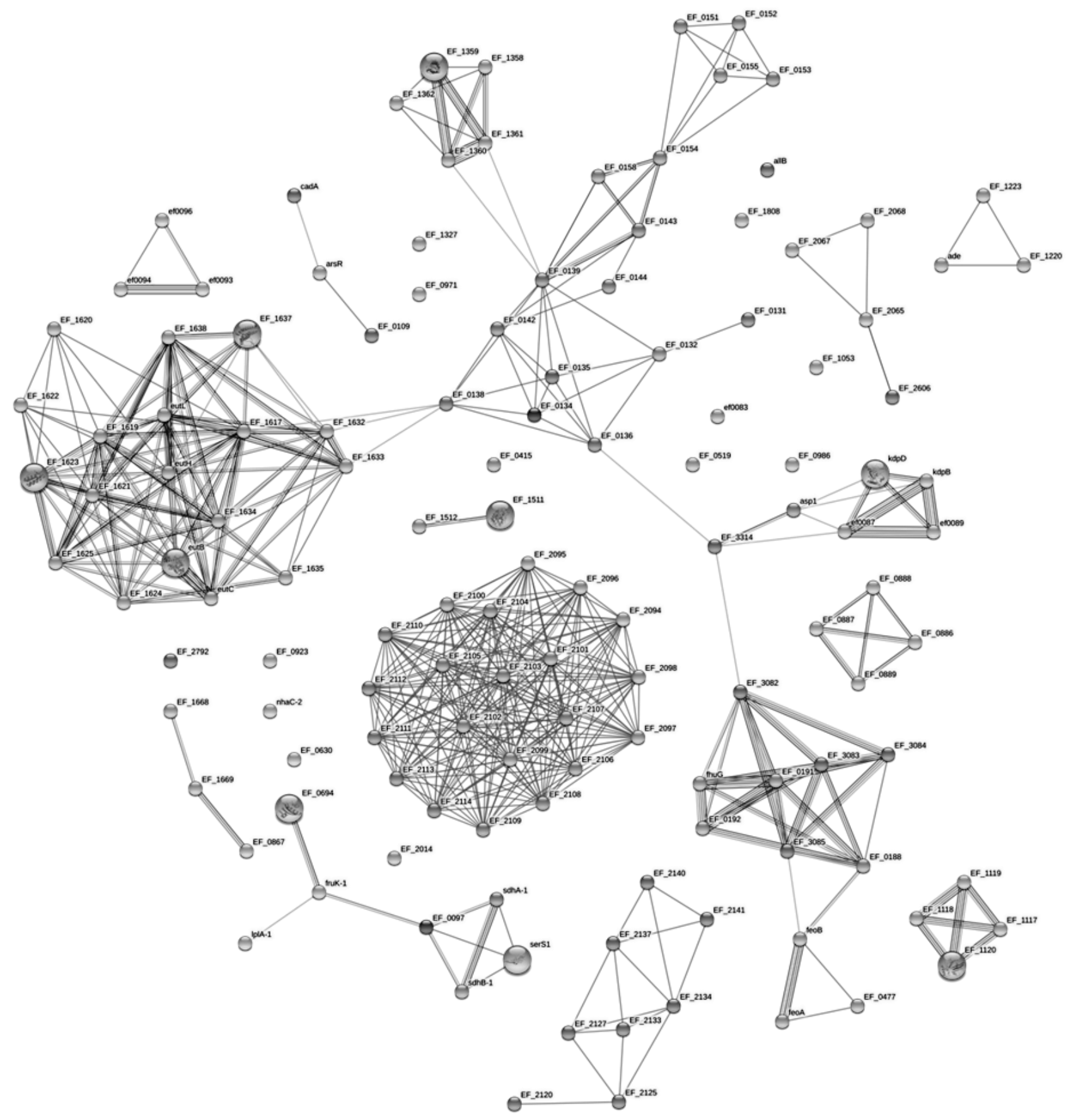

Fig. 3 